\title{
P21 Ser31Arg and FGFR2 rs2981582 Polymorphisms as Risk Factors for Early Onset of Breast Cancer in Yogyakarta, Indonesia
}

\author{
Dewajani Purnomosari*, Clarista Raharjo², Alvin Santoso Kalim², Rahma \\ Herviastuti², Markus Yushan², Rangga Athilah Fajar², Karina Kazia Harris ${ }^{2}$, \\ Artanto Wahyono ${ }^{3}$
}

\begin{abstract}
Objectives: Breast cancer tend to be more progressive with poorer prognosis in younger patients than those at an older age. Single Nucleotide Polymorphisms (SNPs) of P53 Pro72Arg, MDM2 SNP309, P21 Ser31Arg, ER SNP594, HER2 Ile655Val, and FGFR2 rs2981582 have drawn attention as genetic factors associated with cancer risk. However, there were contradictory results involving different races and their association is still unknown in Indonesian populations. This study was performed to examine the proportion of these six genes polymorphisms and their associations with age of onset of breast cancer patients in Yogyakarta, Indonesia. Methods: Biorepository DNA from 199 patients registered at Dr. Sardjito Hospital Yogyakarta from 2006-2013 were tested for polymorphisms using the PCR-RFLP method. Samples were taken from two age groups; early-onset ( $<40$ years) and late-onset of breast cancer ( $>55$ years). Chisquare tests with odds ratio were used for data analysis. Results: The mean age of the early-onset group was $36 \pm 4.2$ years, while the late-onset group was $62 \pm 6.9$ years. AA genotype and A allele of $P 21$ and TT genotypes and T allele of FGFR 2 were significantly more frequent and were associated with an increased risk of early-onset of breast cancer (95\%CI: 2.54 and 1.59; 2.63 and 1.64, respectively). Conclusions: Our study indicates that the A allele of $P 21$ and the allele $\mathrm{T}$ of FGFR2 may be associated with an increased risk of early-onset of breast cancer in Yogyakarta, Indonesia. Further analysis is needed to confirm the findings.
\end{abstract}

Keywords: Age of onset- breast carcinoma- FGFR2- P21- single nucleotide polymorphism

Asian Pac J Cancer Prev, 20 (11), 3305-3309

\section{Introduction}

Globally, breast cancer (BC) ranks highest and is the most prevalent carcinoma among women in Indonesia, accounting for 48.998 new cases $(30.5 \%)$ with 5 years prevalence of 171.005 (41.7\%) (Ferlay, 2013). Early onset $\mathrm{BC}$ occurs in patients aged 40 years or younger and its incidence varies among races (Anders et al., 2009). Early onset ofBC tends to occur with hormone receptor negativity in larger and more aggressive, high grade tumors with hormone receptor negativity, and HER2 overexpression (Assi et al., 2013), with greater risk of contralateral breast cancer in 15 years (Metcalfe et al., 2011).

In the United States, only $6.8 \%$ of $\mathrm{BC}$ patients are below 40 years (Anders et al., 2009), whereas in Asia its incidence rate could reaches 9.5-11\% (Han et al., 2004). Early onset cases in Dr. Sardjito Hospital Yogyakarta between the years 2012-2015 showed incidence rates ranging from 12.8 - 19.7\% (unpublished data).

One of the major risk factors for early onset $\mathrm{BC}$ is a history of $\mathrm{BC}$ in the family, which involves inherited genetic mutations, in particular the major susceptibility genes $B R C A 1$ and $B R C A 2$. However, BRCA1 and BRCA2 have been shown to account for up to only $15 \%$ of familial early onset BC cases (Stratton and Rahman, 2008). One study in China showed that among early-onset BC without a family history of ovarian or $\mathrm{BC}$, these genes were responsible for about $3 \%$ and $0 \%$, respectively (Chen et al., 2009). The same type of study in Indonesia showed that BRCA1 and $B R C A 2$ were responsible for $8.3 \%$ of the cases (Purnomosari et al., 2007). , accounts for only a small percentage of early-onset non-familial $\mathrm{BC}$, indicating other low penetrance susceptibility genes could exist and play a role in tumorigenesis.

Genetic mutations occur in about $1 \%$ of the population and the most common type of germline variations are single nucleotide polymorphisms (SNPs) (Taylor et al.,

${ }^{1}$ Department of Histology and Cell Biology, ${ }^{3}$ Department of Surgery, Faculty of Medicine, ${ }^{2}$ Undergraduate Programme, Public Health and Nursing, Universitas Gadjah Mada, Jl. Farmako, Sekip Utara, Yogyakarta, Indonesia. *For Correspondence: d.purnomosari@ugm.ac.id 
2001). While SNP usually have little effect individually, polygenic models indicate combinations of genetic mutation, may together contribute to higher risk of cancer (Pharoah et al., 2002). A number of SNPs of several genes have been associated with susceptibility to early onset of BC, such as HER2 Ile655Val (Montgomery et al., 2003), MDM2 SNP309 and 553 Arg72Pro (Sun et al., 2009), ER1 594G to A (Yu et al., 2006) and p21 Ser31 Arg (Ma et al., 2006; Qiu et al., 2010). Recent genome-wide association studies have identified genetic variations that may play a role as risk factors for breast cancer in populations of diverse ethnicity (Easton et al., 2007). SNP rs2981582 which lies in intron 2 of FGFR 2 gene is the most significantly associated SNP among eleven SNPs that have been linked with BC (Easton et al., 2007). Further studies also proved the role of FGFR2 rs2981582 as a susceptible gene for early onset of BC (Raskin et al., 2008; Siddiqui et al., 2014), even though like other low penetrance genetic variant studies, the results are not consistent among populations. Thus, the present study aimed to examine the genotypes of $p 53$ Arg72Pro, MDM2 SNP309 T to G, p21 Ser31Arg, HER2 Ile655Val, ER SNP594 G to A, and FGFR2 rs2981582 and their allele frequencies in a clinical group of early onset and late onset $\mathrm{BC}$ patients and to test for any correlations between certain genotypes or alleles with the risk of developing early onset BC in Yogyakarta, Indonesia.

\section{Materials and Methods}

\section{Study population and sample collection}

This research was a hospital-based case control study that included 98 early-onset BC cases $(<40$ years old at diagnosis) and 101 late-onset cases ( $>55$ years old) as the controls. These cases were pathologically diagnosed and recruited between the year 2006 - 2013 at the Dr. Sardjito Hospital Yogyakarta Province Indonesia. The study received approval from the Medical and Health Research Ethics Committee of Faculty of Medicine Universitas Gadjah Mada (KE/FK/779/EC and KE/FK/570/EC/2015).

\section{DNA extraction and genotyping}

Spectrophotometric measurement of the absorbance ratio 260/280 nm were used to determine DNA purity and concentration. Genotyping of the 6 genes was performed using Polymerase chain reaction-restriction fragment length polymorphisms (PCR-RFLP) assay. Details of selected SNPs, primer sequences used for PCR, sizes of PCR products and restriction endonuclease, (New England Biolabs, Ipswich, Massachusetts, United States) used for digestion are described (Table 1). Restriction digested fragments from all of the SNPs were analyzed with 3\% agarose gel electrophoresis (except for FGFR2, 4\% of agarose).

\section{Statistical analyses}

Data analysis used SPSS-21 software (IBM Corp., Chicago). The Hardy-Weinberg equilibrium was first applied to both case and control groups, separately for each variant before association analyses. Significance level $(\alpha)$ used was $5 \%$. To calculate odds ratios (ORs), unconditional logistic regression model were used with 95\% confidence interval (CI) as estimates of relative risk (RR) for the single locus alleles and genotypes.

\section{Results}

In this hospital-based case and control study, we analyzed 6 genes' polymorphisms in 98 early-onset BC patients and 101 late-onset $\mathrm{BC}$ patients as the controls. The mean age at diagnosis for early-onset group was $36 \pm 4.2$ years, while the late-onset group was $62 \pm 6.9$ years. The Hardy-Weinberg equilibrium analysis showed no significant deviations between early and late-onset BC patients ( $p>0.05$; data not shown).

Genotype distribution of each evaluated gene can be found in Table 2. Four genes showed high frequency in heterozygote genotypes, i.e. Arg/Pro of $p 53, \mathrm{~T} / \mathrm{G}$ of $M D M 2, \mathrm{~A} / \mathrm{C}$ of $p 21$ and $\mathrm{C} / \mathrm{T}$ of $F G F R 2$ with proportion of $48 \%, 55.1 \%, 45.9 \%$ and $45.9 \%$, respectively. There was no different proportion between early and late onset cases. On the other hand, genotype frequencies of HER2 and ER1 were different from the other 4 genes, as the most frequent genotype for HER2 was the homozygote wildtype (Ile/Ile), while for ER1 it was the homozygote mutant $(\mathrm{G} / \mathrm{G})$.

Table 1. Primers and Restriction Enzyme Used for Genotyping 6 Genes

\begin{tabular}{|c|c|c|c|c|c|c|}
\hline Gene & SNP & rs number & & primer & PCR product & enzyme \\
\hline \multirow[t]{2}{*}{ p53 } & Pro72Arg & rs 1042522 & $\mathrm{~F}$ & 5'- TTG CCG TCC CAA GCA ATG GAT GA -3' & $199 \mathrm{bp}$ & Bstu1 \\
\hline & & & $\mathrm{R}$ & 5'- TCT GGG AAG GGA CAG AAG ATG A -3' & & \\
\hline \multirow[t]{2}{*}{ MDM2 } & $309 \mathrm{~T}>\mathrm{G}$ & rs2279744 & $\mathrm{F}$ & 5'- GAT TTC GGA CGG CTC TCG CGG C-3' & $121 \mathrm{bp}$ & PstI \\
\hline & & & $\mathrm{R}$ & 5'- CAT CCG GAC CTC CCG CGC TG-3' & & \\
\hline \multirow[t]{2}{*}{ HER2 } & Ile655Val & rs1136201 & $\mathrm{F}$ & 5'- AGA GAG CCA GCC CTC TGA CGT CCA T- 3' & $148 \mathrm{bp}$ & BsmAI \\
\hline & & & $\mathrm{R}$ & 5'- TCC GTT TCC TGC AGC AGT CTC CGC A -3' & & \\
\hline \multirow[t]{2}{*}{ ER1 } & $594 \mathrm{~A}>\mathrm{G}$ & rs 2228480 & $\mathrm{~F}$ & 5'- GAG GAG ACG GAC CAA AGC CAC -3' & $227 b p$ & BtgI \\
\hline & & & $\mathrm{R}$ & 5'- GCC ATT GGT GTT GGA TGC ATG C -3' & & \\
\hline \multirow[t]{2}{*}{ p21 } & Ser31Arg & rs 1801270 & $\mathrm{~F}$ & 5'- ATA GTG TCT AAT CTC CGC CG -3' & $245 \mathrm{bp}$ & Blp1 \\
\hline & & & $\mathrm{R}$ & 5'- AAG TCA CCC TCC AGT GGT GT -3' & & \\
\hline \multirow[t]{2}{*}{ FGFR2 } & - & rs 2981582 & $\mathrm{~F}$ & 5'- CCC TTT GGA GAC AAC GTG AGC C- 3' & $176 \mathrm{bp}$ & HinP1I \\
\hline & & & $\mathrm{R}$ & 5'- CAG GCA CCA GGT GGA CTC TGC-3' & & \\
\hline
\end{tabular}


Table 2. Genotype and Allelic Frequencies of P53 Pro72Arg, MDM2 SNP309, P21 Ser31Arg, ER SNP594, HER2 Ile655Val, and FGFR2 rs2981582 in Breast Cancer Patients with Different Age of Onset

\begin{tabular}{|c|c|c|c|c|c|c|}
\hline Polymophisms & Genotype/Allele & Cases $(<40) n=98$ & Controls $(>=55) \mathrm{n}=101$ & p-value & OR & $95 \% \mathrm{CI}$ \\
\hline \multirow[t]{5}{*}{ HER2 Ile133Val } & $\mathrm{I} / \mathrm{I}$ & $73(74.5 \%)$ & $74(73.3 \%)$ & 0.614 & ref & ref \\
\hline & $\mathrm{I} / \mathrm{V}$ & $21(21.4 \%)$ & $25(24.8 \%)$ & & 0.852 & $0.42-1.74$ \\
\hline & $\mathrm{V} / \mathrm{V}$ & $4(4.1 \%)$ & $2(2.0 \%)$ & & 2,027 & $0.31-16.51$ \\
\hline & I & $167(85.2 \%)$ & $173(85.6 \%)$ & 0.901 & 1,036 & $0.57-1.87$ \\
\hline & $\mathrm{V}$ & $29(14.8 \%)$ & $29(14.3 \%)$ & & & \\
\hline \multirow[t]{5}{*}{ ER1 594A $>$ G } & $\mathrm{A} / \mathrm{A}$ & $5(5.1 \%)$ & $5(5 \%)$ & 0.52 & ref & ref \\
\hline & $\mathrm{A} / \mathrm{G}$ & $35(35.7 \%)$ & $44(43.6 \%)$ & & 0.713 & $0.38-1.33$ \\
\hline & $\mathrm{G} / \mathrm{G}$ & $58(59.2 \%)$ & $52(51.5 \%)$ & & 0.897 & $0.21-3.84$ \\
\hline & A & $45(23 \%)$ & $54(26.7 \%)$ & 0.384 & 0.817 & $0.51-1.32$ \\
\hline & G & $151(77 \%)$ & $148(73.3 \%)$ & & & \\
\hline \multirow[t]{5}{*}{ p53 Arg72Pro } & $\mathrm{A} / \mathrm{A}$ & $33(33.7 \%)$ & $25(24.8 \%)$ & 0.183 & ref & ref \\
\hline & $\mathrm{A} / \mathrm{P}$ & $47(48 \%)$ & $50(49.5 \%)$ & & 0.637 & $0.31-1.29$ \\
\hline & $\mathrm{P} / \mathrm{P}$ & $18(18.4 \%)$ & $26(25.7 \%)$ & & 0.489 & $0.20-1.17$ \\
\hline & A & $114(58.2 \%)$ & $99(49.0 \%)$ & 0.067 & 0.691 & $0.46-1.05$ \\
\hline & $\mathrm{P}$ & $82(41.8 \%)$ & $103(51.0 \%)$ & & & \\
\hline \multirow[t]{5}{*}{ MDM2 SNP309 } & $\mathrm{T} / \mathrm{T}$ & $20(20.5 \%)$ & $23(22.8 \%)$ & 0.644 & ref & ref \\
\hline & $\mathrm{T} / \mathrm{G}$ & $54(55.1 \%)$ & $49(48.5 \%)$ & & 0.789 & $0.39-1.61$ \\
\hline & $\mathrm{G} / \mathrm{G}$ & $24(24.5 \%)$ & $29(28.7 \%)$ & & 1.051 & $0.47-2.36$ \\
\hline & $\mathrm{T}$ & 94 (48.0\%) & $95(47.0 \%)$ & 0.853 & 1.038 & $0.7-1.54$ \\
\hline & $\mathrm{G}$ & $102(52.0 \%)$ & $107(53.0 \%)$ & & & \\
\hline \multirow[t]{5}{*}{ p21 Ser31Arg } & $\mathrm{C} / \mathrm{C}$ & $21(21.4 \%)$ & $30(29.7 \%)$ & $0.047^{*}$ & ref & ref \\
\hline & $\mathrm{C} / \mathrm{A}$ & $45(45.9 \%)$ & $53(52.5 \%)$ & & 1.213 & $0.61-2.41$ \\
\hline & $\mathrm{A} / \mathrm{A}$ & $32(32.7 \%)$ & $18(17.8 \%)$ & & 2.54 & $1.14-5.67$ \\
\hline & $\mathrm{C}$ & 87 (44.4\%) & $113(56 \%)$ & $0.021^{*}$ & 1.591 & $1.07-2.36$ \\
\hline & A & $109(55.6 \%)$ & $89(44 \%)$ & & & \\
\hline \multirow[t]{5}{*}{ FGFR2 rs2981582 } & $\mathrm{C} / \mathrm{C}$ & $26(26.5 \%)$ & $37(36.6 \%)$ & 0.091 & ref & ref \\
\hline & $\mathrm{C} / \mathrm{T}$ & $45(45.9 \%)$ & $48(47.5 \%)$ & & 1.334 & $0.70-2.55$ \\
\hline & $\mathrm{T} / \mathrm{T}$ & $27(27.5 \%)$ & $16(15.8 \%)$ & & 2.401 & $1.08-5.32$ \\
\hline & $\mathrm{C}$ & $97(49.5 \%)$ & $122(60.4 \%)$ & $0.028^{*}$ & 1.556 & $1.05-2.32$ \\
\hline & $\mathrm{T}$ & $99(50.5 \%)$ & $80(39.6 \%)$ & & & \\
\hline
\end{tabular}

*, $\mathrm{p}<0.05$; OR, odds ratio; CI, confidence interval

Genotype $\mathrm{C} / \mathrm{C}$ of $\mathrm{P} 21$ was mostly found in late onset compared to early onset cases $(29.7 \%$ vs $21.4 \%)$, while frequency of genotype A/A was higher in early onset compared to late onset ( $32.7 \%$ vs $17.8 \%)$. There were significant differences in frequency of p21 A/A and allele A found through Chi square tests in the younger group compared to older cases $(\mathrm{p}=0.047$ and $\mathrm{p}=0.021$, respectively). Similar circumstance was found in FGFR2 genes, where frequency of $\mathrm{C} / \mathrm{C}$ genotype was higher in late onset compared to early onset ( $36.6 \%$ vs $26.5 \%$ ), while $\mathrm{T} / \mathrm{T}$ genotype was higher in early onset compared to late onset cases $(27.5 \%$ vs $16.8 \%$ ), but the difference was not statistically significant. Allele T was more frequently found in early onset cases compare to late onset $(50.5 \%$ vs $39.6 \%$ ), and the difference was statistically significant $(\mathrm{p}=0.028)$.

Logistic regression models comparing with Ser/Ser (C/C genotype) of $P 21$, found those with Ser/Arg (C/A) and $\mathrm{Arg} / \operatorname{Arg}(\mathrm{A} / \mathrm{A})$ had OR of 1.213 (95\% CI: 0.612-
$2.405)$ and 2.540 (95\% CI: 1.138-5.668), respectively, suggesting that Ser31Arg polymorphisms are correlated with the increased risk of early onset BC. Similarly, T/T genotype and T allele of $F G F R 2$ rs2981582 were found to increase the risk of early onset BC with OR of $2.40(95 \%$ CI: $1.08-5.32)$ and 1.56 (95\% CI: 1.05-2.32) respectively.

\section{Discussion}

Poor prognosis and low survival are linked to early onset of $\mathrm{BC}$ and accordingly, preventive measures by recognizing the risk factors are very much needed. Genetic variations in genes that regulate crucial processes such as cell apoptosis, proliferation and DNA repair are potential candidates for breast cancer risk factors. Recent research that was conducted in many different countries shows different outcomes among different populations.

In this study we evaluated 6 genes thathave been linked with susceptibility to early onset of BC, only two 
of them, $P 21$ and FGFR2 were associated as risk factors in an Indonesian population.

\section{P21 Se31Arg polymorphism}

Results of the present study showed that AA genotype and A allele of $P 21$ were significantly more frequently found in early onset cancer cases and had a 2.540 increased risk of early-onset BC (95\% CI: 1.138-5.668). P21 (also identified as CDKN1A), which encodes p21WAF1/CIP1, a cyclin-dependent kinase inhibitor, is considered to significantly influence cell cycle control (Gartel and Radhakrishnan, 2005). One polymorphism of $P 21$ that has received much attention is Ser31Arg (rs1801270), which substitutes A for $\mathrm{C}$ in the third base of codon 31 of $P 21$ results in a serine to arginine amino acid substitution in the DNA-binding zinc finger motif of the protein (Mousses et al., 1995). Thus, it is very likely this polymorphism is also involved in cancer development (Lukas et al., 1997).

Several results support the role of P21 Ser31Arg polymorphism in $\mathrm{BC}$ risk (Keshava et al., 2002; Ma et al., 2006), but the results are inconclusive, possibly due to small effect of the polymorphism on BC risk and the relatively small number of samples used in the studies.

There have been several studies of P21 Ser31Arg polymorphism that were done to determine the risk of BC incidence. One meta-analysis study by Qiu and colleagues (Qiu et al., 2010) reported that the genotype C/C significantly increased the risk of breast cancer by 1.496 times (95\% CI:1.164-1.924) for Caucasians. However, for the Asian population, there was no statistically significant increase in risk (OR 0.896; 95\% CI:0.424-1.893).

\section{FGFR2 rs2981582 polymorphism}

FGFR2 is a member of the FGFR family that contributes to cell growth, malignancy, motility, and angiogenesis. Various meta-analysis studies have been conducted and reported that SNP FGFR2 rs2981582 TT is linked to an increased risk of $\mathrm{BC}$, but until now the exact mechanism of carcinogenesis linking SNP FGFR2 rs2981582 TT to BC, especially early breast cancer onset has not been found (Zhang et al., 2010; Peng et al., 2011). In this study, frequency of $\mathrm{C} / \mathrm{C}$ genotype was higher in patient with late onset compared to early onset $(36.6 \%$ vs $26.5 \%$ ) while $\mathrm{T} / \mathrm{T}$ genotype was higher in younger cases compared to the older patients $(27.5 \%$ vs $16.8 \%)$, but the result was not statistically significant. Interestingly, proportion of allele $\mathrm{T}$ was significantly different in early onset cases.

SNP FGFR2 rs2981582 intron 2 alters the binding of two transcription factors, Oct-1 / Runx2 and C / $\mathrm{EBpb}$, resulting in increased expression of the FGFR2 gene in cell lines and mammary tissue (Jia et al., 2010). This overexpression is confirmed by the study of Rebbeck (Rebbeck et al., 2009) that reported FGFR2 over expression occurs in $10-15 \%$ of breast tumors, but FGFR2 expression is lower in normal breast tissue in someone who has T allele (Sun et al., 2010). In addition, the in vitro evidence also shows that the mechanism of carcinogenesis of the SNP is more directed toward the anti-apoptosis effect than the mitogenic effects which are partly mediated through the down-regulation of FOXO protein synthesis. Amplification of the FGFR2 gene due to SNP results in an increase in intracellular screening which affects the decrease of FOXO protein. FOXO proteins are involved in apoptotic induction, DNA damage repair, ROS detoxification, and down-regulation of ER-alpha and ER-beta transcription activities. Therefore, decreased protein synthesis of FOXO will decrease apoptosis, ROS detoxification function, DNA repair, and down-regulation of ER transcription activity (Murillo-Zamora et al., 2013).

All of the above findings significantly support our results that show FGFR2 gene polymorphism rs2981582 TT can be linked to increased risk of early onset BC in Yogyakarta, Indonesia. This finding is consistent with a study conducted by Fu et al., (2012) which stated that TT and T allele genotypes in FGFR2 polymorphism rs2981582 increase the risk of early-onset BC in South Chinese Han populations with ORs of 3.062 (95\% CI: 1.229-7.629) and 1.606 (95\% CI: 1.084-2.380), respectively. But in the study, the controls used were healthy women, as well as the age-appropriate early-onset BC limit was $<35$ years. There is no similar study that discusses the relationship of early onset of breast cancer and FGFR2 polymorphism in other populations, but a study by Liang (Liang et al., 2008) found that there is a strong association of TT mutant genotypes and T alleles in FGFR2 polymorphism rs2981582 as risk factors of occurrence of $\mathrm{BC}$ in premenopausal women.

Our study indicates that the A allele of $P 21$ and the allele T of FGFR2 may be linked to increased risk of earlyonset BC in Yogyakarta, Indonesia. In order to confirm the findings, further analyses are needed.

\section{Funding statement}

This study received grant support from Dana Masyarakat Faculty of Medicine Universitas Gadjah Mada 2015 and 2016.

\section{Presentation statement}

The manuscript has been presented as poster presentation in 9th General Assembly and International Conference 2018. Asian Pacific Organization for Cancer Prevention, Jeju Island, South Korea, 19-20 April 2018

\section{References}

Anders CK, Johnson R, Litton J, et al (2009). Breast cancer before age 40 years. Semin Oncol, 36, 237-49.

Assi HA, Khoury KE, Dbouk H, et al (2013). Epidemiology and prognosis of breast cancer in young women. $J$ Thorac Dis, 5, 2-8.

Chen W, Pan K, Ouyang T, et al (2009). BRCA1 germline mutations and tumor characteristics in Chinese women with familial or early-onset breast cancer. Breast Cancer Res Treat, 117, 55-60.

Easton DF, Pooley KA, Dunning AM, et al (2007). Genome-wide association study identifies novel breast cancer susceptibility loci. Nature, 447, 1087-93.

Ferlay J SI, Ervik M, Dikshit R, et al (2013). GLOBOCAN 2012 v1.0, Cancer Incidence and Mortality Worlwide [Online]. Available: http://globocan.iarc.fr/ No.11 [Internet]].

Fu F, Wang C, Huang M, et al (2012). Polymorphisms in second 
intron of the FGFR2 gene are associated with the risk of early-onset breast cancer in Chinese Han women. Tohoku $J$ Exp Med, 226, 221-9.

Gartel AL, Radhakrishnan SK (2005). Lost in transcription: p21 repression, mechanisms, and consequences. Cancer Res, 65, 3980-5.

Han W, Kim SW, Park IA, et al (2004). Young age: an independent risk factor for disease-free survival in women with operable breast cancer. BMC Cancer, 4, 82.

Jia C, Cai Y, Ma Y, et al (2010). Quantitative assessment of the effect of FGFR2 gene polymorphism on the risk of breast cancer. Breast Cancer Res Treat, 124, 521-8.

Keshava C, Frye BL, Wolff MS, et al (2002). Waf-1 (p21) and p53 polymorphisms in breast cancer. Cancer Epidemiol Biomarkers Prev, 11, 127-30.

Liang J, Chen P, Hu Z, et al (2008). Genetic variants in fibroblast growth factor receptor 2 (FGFR2) contribute to susceptibility of breast cancer in Chinese women. Carcinogenesis, 29, 2341-6.

Lukas J, Groshen S, Saffari B, et al (1997). WAF1/Cip1 gene polymorphism and expression in carcinomas of the breast, ovary, and endometrium. Am J Pathol, 150, 167-75.

$\mathrm{Ma} \mathrm{H}$, Jin G, Hu Z, et al (2006). Variant genotypes of CDKN1A and CDKN1B are associated with an increased risk of breast cancer in Chinese women. Int J Cancer, 119, 2173-8.

Metcalfe K, Gershman S, Lynch HT, et al (2011). Predictors of contralateral breast cancer in BRCA1 and BRCA2 mutation carriers. Br J Cancer, 104, 1384-92.

Montgomery KG, Gertig DM, Baxter SW, et al (2003). The HER 2 I655V polymorphism and risk of breast cancer in women $<$ age 40 years. Cancer Epidemiol Biomarkers Prev, 12, 1109-11.

Mousses S, Ozcelik H, Lee PD, et al (1995). Two variants of the CIP1/WAF1 gene occur together and are associated with human cancer. Hum Mol Genet, 4, 1089-92.

Murillo-Zamora E, Moreno-Macias H, Ziv E, et al (2013). Association between rs2981582 polymorphism in the FGFR2 gene and the risk of breast cancer in Mexican women. Arch Med Res, 44, 459-66.

Peng S, Lu B, Ruan W, et al (2011). Genetic polymorphisms and breast cancer risk: evidence from meta-analyses, pooled analyses, and genome-wide association studies. Breast Cancer Res Treat, 127, 309-24.

Pharoah PD, Antoniou A, Bobrow M, et al (2002). Polygenic susceptibility to breast cancer and implications for prevention. Nat Genet, 31, 33-6.

Purnomosari D, Pals G, Wahyono A, et al (2007). BRCA1 and BRCA2 germline mutation analysis in the Indonesian population. Breast Cancer Res Treat, 106, 297-304.

Qiu LX, Zhang J, Zhu XD, et al (2010). The p21 Ser31Arg polymorphism and breast cancer risk: a meta-analysis involving 51,236 subjects. Breast Cancer Res Treat, 124, 475-9.

Raskin L, Pinchev M, Arad C, et al (2008). FGFR2 is a breast cancer susceptibility gene in Jewish and Arab Israeli populations. Cancer Epidemiol Biomarkers Prev, 17, 1060-5.

Rebbeck TR, DeMichele A, Tran TV, et al (2009). Hormone-dependent effects of FGFR2 and MAP3K1 in breast cancer susceptibility in a population-based sample of post-menopausal African-American and European-American women. Carcinogenesis, 30, 269-74.

Siddiqui S, Chattopadhyay S, Akhtar MS, et al (2014). A study on genetic variants of Fibroblast growth factor receptor 2 (FGFR2) and the risk of breast cancer from North India. PLoS One, 9, e110426.

Stratton MR, Rahman N (2008). The emerging landscape of
DNA Polymorphisms and Early Onset Breast Cancer

breast cancer susceptibility. Nat Genet, 40, 17-22.

Sun C, Olopade OI, Di Rienzo A (2010). rs2981582 is associated with FGFR2 expression in normal breast. Cancer Genet Cytogenet, 197, 193-4.

Sun YF, Leu JD, Chen SM, et al (2009). Results based on 124 cases of breast cancer and 97 controls from Taiwan suggest that the single nucleotide polymorphism (SNP309) in the $M D M 2$ gene promoter is associated with earlier onset and increased risk of breast cancer. BMC Cancer, $\mathbf{9}, 13$.

Taylor JG, Choi EH, Foster CB, et al (2001). Using genetic variation to study human disease. Trends $\mathrm{Mol} \mathrm{Med,7,}$ $507-12$.

Yu JC, Hsu HM, Chen ST, et al (2006). Breast cancer risk associated with genotypic polymorphism of the genes involved in the estrogen-receptor-signaling pathway: a multigenic study on cancer susceptibility. J Biomed Sci, 13, 419-32.

Zhang J, Qiu LX, Wang ZH, et al (2010). Current evidence on the relationship between three polymorphisms in the FGFR2 gene and breast cancer risk: a meta-analysis. Breast Cancer Res Treat, 124, 419-24.

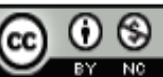

This work is licensed under a Creative Commons AttributionNon Commercial 4.0 International License. 